\title{
Fractalkine-induced smooth muscle cell proliferation in pulmonary hypertension
}

\author{
F. Perros*, , P. Dorfmüller*,\#, R. Souza*, I. Durand-Gasselin\#, V. Godot", F. Capel", \\ S. Adnot ${ }^{\top}$, S. Eddahibi ${ }^{\top}$, M. Mazmanian ${ }^{+}$, E. Fadel $^{+}$, P. Hervé $^{+}$, G. Simonneau*, $^{*}$ \\ D. Emilie ${ }^{\#}$ and M. Humbert*,\#
}

ABSTRACT: Pulmonary hypertension is characterised by a progressive increase in pulmonary arterial resistance due to endothelial and smooth muscle cell proliferation resulting in chronic obstruction of small pulmonary arteries. There is evidence that inflammatory mechanisms may contribute to the pathogenesis of human and experimental pulmonary hypertension.

The aim of the study was to address the role of fractalkine (CX3CL1) in the inflammatory responses and pulmonary vascular remodelling of a monocrotaline-induced pulmonary hypertension model.

The expression of CX3CL1 and its receptor CX3CR1 was studied in monocrotaline-induced pulmonary hypertension by means of immunohistochemistry and quantitative reverse-transcription PCR on laser-captured microdissected pulmonary arteries.

It was demonstrated that CX3CL1 was expressed by inflammatory cells surrounding pulmonary arterial lesions and that smooth muscle cells from these vessels had increased CX3CR1 expression. It was then shown that cultured rat pulmonary artery smooth muscle cells expressed CX3CR1 and that CX3CL1 induced proliferation but not migration of these cells.

In conclusion, the current authors proposed that fractalkine may act as a growth factor for pulmonary artery smooth muscle cells. Chemokines may thus play a role in pulmonary artery remodelling.

KEYWORDS: Chemokines, fractalkine, proliferation, pulmonary hypertension, smooth muscle cell

$\mathbf{P}$ ulmonary arterial hypertension (PAH) is characterised by a progressive increase in pulmonary vascular resistance leading to right ventricular failure [1]. The main pathological finding related to PAH is an abnormal pulmonary artery endothelial and smooth muscle cell (PASMC) proliferation resulting in obstruction of small pulmonary arteries [2, 3]. In addition, there is evidence that inflammatory events may also be involved in its pathogenesis. Indeed, it is established that PAH can develop as a consequence of systemic inflammatory conditions, such as connective tissue diseases [4]. Furthermore, the presence of mononuclear cells and lymphocyte infiltration in plexiform lesions indicates that inflammatory mechanisms may have a role inciting, modulating or resulting in developmental events of PAH [5]. The relevance of inflammatory events in PAH patients has been further supported by significant clinical and haemodynamic improvements in patients receiving corticosteroids and/or cyclophosphamide in the setting of PAH-complicating systemic diseases $[6,7]$.

The current authors hypothesised that mediators involved both in inflammatory responses and pulmonary vascular remodelling may at least partially explain the link between inflammation and PAH. The relationship of PAH to mutations of genes encoding receptors for members of the transforming growth factor- $\beta$ family $[8,9]$ has clearly highlighted a central role for cytokines in pulmonary vascular homeostasis. Furthermore, overexpression of platelet-derived growth factor (PDGF) in human PAH, as well as in monocrotaline-exposed rats, has led to novel hypotheses and therapeutic strategies based on PDGF pathway inhibition with imatinib [10-13]. Finally, pro-inflammatory cytokines and chemokines are produced in excess in patients displaying severe PAH [14-16], suggesting a role in the chain of events promoting PAH occurrence and/ or progression.
AFFILIATIONS

*UPRES EA2705, Service de Pneumologie, Centre National de Référence de l'Hypertension Artérielle Pulmonaire, Hôpita Antoine-Béclère, AssistancePublique Hôpitaux de Paris, Université Paris-Sud 11

\# Institut National de la Santé et de la Recherche Médicale, U764, Institut Fédératif de Recherche 13, Clamart, "INSERM U651, Université Paris 12 Créteil, and

+UPRES EA2705, Laboratoire de Chirurgie Expérimentale, Centre Chirurgical Marie Lannelongue, Université Paris-Sud 11, Le Plessis Robinson, France.

\section{CORRESPONDENCE}

M. Humbert: Service de Pneumologie et Réanimation Respiratoire, Hôpital Antoine-Béclère, 157 rue de la Porte de Trivaux, 92140 Clamart, France. Fax: 33146303824

E-mail: marc.humbert@abc.aphp.fr

Received:

August 102006

Accepted after revision:

December 112006

SUPPORT STATEMENT

F. Perros was supported by a grant from Ministère de la Recherche (Paris, France). R. Souza was supported by a grant from the European Respiratory Society. The South Paris Pulmonary Hypertension Centre for Research and Care (Paris, France) was supported in part by grants from Chancellerie des Universités, Legs Poix, Université Paris-Sud 11 (Paris, France) and Institut des Maladies Rares (Paris, France). This research project receive financial support from the European Commission under the 6th Framework Programme (Contract No: LSHM-CT2005-018725, PULMOTENSION)

European Respiratory Journa Print ISSN 0903-1936 Online ISSN 1399-3003 
Chemokines belong to a family of soluble proteins known to induce leukocyte migration and activation. Fractalkine (CX3CL1) is a unique chemokine in that it exists in both a soluble form and in a membrane-anchored form on endothelial cells [17]. It is normally expressed in neurons and other nonlymphoid lineages, such as endothelial and epithelial cells [18-21], and acts through a transmembrane receptor (CX3CR1) expressed in several cellular types, including monocytes and T-lymphocytes [22, 23]. There is a growing interest in chemokines in vascular disorders, as they have been shown to have a significant effect after endothelial injury [20]. High levels of CX3CL1 have been measured in advanced atherosclerotic arteries [24, 25]. Importantly, CX3CL1 may act beyond inflammatory cell recruitment, as suggested by its proliferative effect on smooth muscle cells demonstrated in atherosclerosis [26]. Due to the major role of PASMC proliferation in PAH, the current authors hypothesised that CX3CL1 may have a role in pulmonary vascular remodelling. For that purpose, increased CX3CL1 and CX3CR1 expression was demonstrated in the lungs and pulmonary arteries of rats displaying monocrotalineinduced pulmonary hypertension. Based on these data and the previous demonstration of CX3CL1 overexpression in the lungs of PAH patients [15], the current authors then demonstrated that rat PASMC could express CX3CR1 and that CX3CL1 may act as a growth factor for PASMC.

\section{METHODS}

\section{Animal model}

Young male albino Wistar rats received a single subcutaneous injection of $60 \mathrm{mg} \cdot \mathrm{kg}^{-1}$ monocrotaline (Sigma-Aldrich, Saint Quentin Fallavier, France) or saline. Ten animals (five saline and five monocrotaline-exposed) were sacrificed on days $0,0.5$, $1,5,10,15$ and 21, after complete haemodynamic analysis, as previously described [27]; lungs were then explanted and stored at $-80^{\circ} \mathrm{C}$. Right ventricular hypertrophy was analysed via the weight ratio of the right ventricle $(\mathrm{RV})$ over that of the left ventricle (LV) plus septum (S): RV/(LV+S).

\section{Primary smooth muscle cell cultures}

At baseline (control) and 21 days after being exposed to monocrotaline, five rats were killed by an overdose of pentobarbital. The lungs were immediately removed and proximal pulmonary arteries were isolated. Smooth muscle cells were obtained by enzymatic digestion as previously described [28].

\section{Immunohistochemistry}

Immunohistochemistry was performed on 8 - $\mu$ m-thick sections of frozen tissue or on PASMC grown on Labtek eight-well chamber slides (Dominique Dutscher, Brumath, France). After routine preparation, slides were processed with the following antibodies: anti-CD3 (T-lymphocytes, 1F4; Serotec, Cergy Saint-Christophe, France), anti-CD68 (macrophages, ED1; Serotec), anti-CX3CL1 (TP203; CliniSciences, Montrouge, France) and anti-CX3CR1 (TP502; AbCys, Paris, France). Controls used for these antibodies included omission of the primary antibody and substitution of the primary antibody by rabbit immunoglobulin G. Laser capture microdissection and $\mathrm{CDNA}$ preparation of
bronchus-associated pulmonary arteries

Pulmonary artery media of a cross-sectional diameter of 100$200 \mu \mathrm{m}$ were captured using the AS LMD laser microdissection microscope (Leica, Rueil-Malmaison, France). RNA was extracted from microdissected pulmonary arteries with a picopure RNA isolation kit (Alphelys, Plaisir, France) and then eluted from silicate columns and reverse-transcribed using Sensiscript Reverse Transcription kit (Qiagen, Courtaboeuf, France).

Gene quantification by real-time reverse transcription PCR Total lung PCR reactions were carried out with SYBR Green reagents and were followed in an ABI Prism7000 Sequence Detection System (Applied Biosystems, Courtaboeuf, France). Oligonucleotide primers were designed using the Primer Express software, based on sequences from the GenBank database (18s ribosomal RNA (rRNA) forward (F): 5'-AAGTCCCTGCCCTTTGTACACA-3', reverse (R): 5'-GATCCGAGGGCCTCACTAAAC-3', GenBank Accession X01117; cx3cl1 F: 5'TGCACAGCCCAGATCATTCA-3', R: 5'-CTGCGCTCTCAGATGTAGGAAA-3', GenBank Accession NM_134455; cx3cr1 F: 5'GGAGCAGGCAGGACAGCAT-3', R: 5'-CCCTCTCCCTCGCTTGTGTA-3', GenBank Accession NM_133534). For nanoquantities of cDNA obtained by microdissection, Applied Biosystems TaqMan Gene Expression Assays were used with TaqMan Universal PCR Master Mix (Applied Biosystems). Results were analysed with ABI Prism 7000 SDS Software using the second derivative maximum method to set cycle threshold with $18 \mathrm{~s}$ rRNA as an internal housekeeping gene control.

\section{Western blot analysis}

Western blot analysis of CX3CR1 in PASMC was performed as previously described [29].

\section{Measurement of PASMC proliferation}

PASMC were serum-starved for $48 \mathrm{~h}$, then incubated with recombinant rat $\mathrm{CX} 3 \mathrm{CL1}$ or recombinant rat $\mathrm{PDGF-BB}$ (R\&Dsystem, Lille, France) and $\left[{ }^{3} \mathrm{H}\right]$ thymidine (Amersham, Pharmacia Biotech UK Ltd, Little Chalfont, UK) for $24 \mathrm{~h}$. Cell proliferation was detected by the measurement of thymidine incorporation [30].

\section{Migration assay}

Trypsinised PASMC were transferred into the upper chambers of 8 - $\mu \mathrm{m}$-pore transwell plates (vWR, Fontenay-sous-Bois, France). Recombinant rat CX3CL1 or recombinant rat PDGF$\mathrm{BB}$ was added to the lower chamber. After $24 \mathrm{~h}$ at $37^{\circ} \mathrm{C}$, migration was quantified by counting cells in the bottom of the membrane stained with Diff Quick (Dade Behring, Paris, France). The number of cells on the lower surface of the filter was counted in eight fields by light microscopy under high power $(\times 200)$. Actin polymerisation assays were performed as previously described [31].

\section{Statistical analysis}

Results are presented as mean \pm SEM, unless otherwise stated. ANOVA for repeated measures was used for multiple groups comparison, with Fisher's projected least significant difference test for the post hoc analysis. 


\section{RESULTS}

\section{Haemodynamics and right ventricular hypertrophy in} monocrotaline-exposed rats

Control rats had a mean pulmonary artery pressure $(P$ pa $)$ of $14 \pm 1 \mathrm{mmHg}$ and a total pulmonary vascular resistance (TPVR) of $23 \pm 1$ units $\cdot \mathrm{kg}^{-1}$, while all monocrotaline-exposed rats had pulmonary hypertension at day 21 (mean $P$ pa $=28 \pm 2 \mathrm{mmHg}$, $\mathrm{TPVR}=56 \pm 5$ units $\left.\cdot \mathrm{kg}^{-1}\right)$. A compensatory RV hypertrophy developed, as demonstrated by the ratio $\mathrm{RV} /(\mathrm{LV}+\mathrm{S})$ $(0.62 \pm 0.03$ in the monocrotaline group versus $0.29 \pm 0.02$ in the control group; $\mathrm{p}<0.0001$ ), which correlated with the mean $P$ pa $\left(\mathrm{r}^{2}=0.65 ; \mathrm{p}<0.0001\right)$ and TPVR $\left(\mathrm{r}^{2}=0.64 ; \mathrm{p}<0.0001\right)$.

\section{CX3CL1 and CX3CR1 expression in rat lungs and microdissected pulmonary arteries}

Whole lung CX3CL1 and CX3CR1 expression was markedly overexpressed after monocrotaline exposure (fig. 1). There was an early gene overexpression immediately after monocrotalineinduced pulmonary injury, with a 29- and 26-fold increase in CX3CL1 and CX3CR1 expression, respectively, at $12 \mathrm{~h}$ compared with baseline values. After this initial peak, CX3CL1 and CX3CR1 gene expression remained elevated compared with baseline values. In order to investigate whether pulmonary artery CX3CL1 and CX3CR1 gene expression was also raised in the pulmonary arterial wall after monocrotaline exposure, the tissue obtained was studied by laser capture microdissection of pulmonary artery from pulmonary hypertensive rats, analysed 21 days after monocrotaline exposure. For that purpose, pulmonary artery media of a cross-sectional diameter of 100 $200 \mu \mathrm{m}$ was microdissected, as shown in figures $2 \mathrm{a}$ and $2 \mathrm{~b}$. In the collected material, it was found that CX3CR1 but not CX3CL1 was overexpressed (fig. 2c).

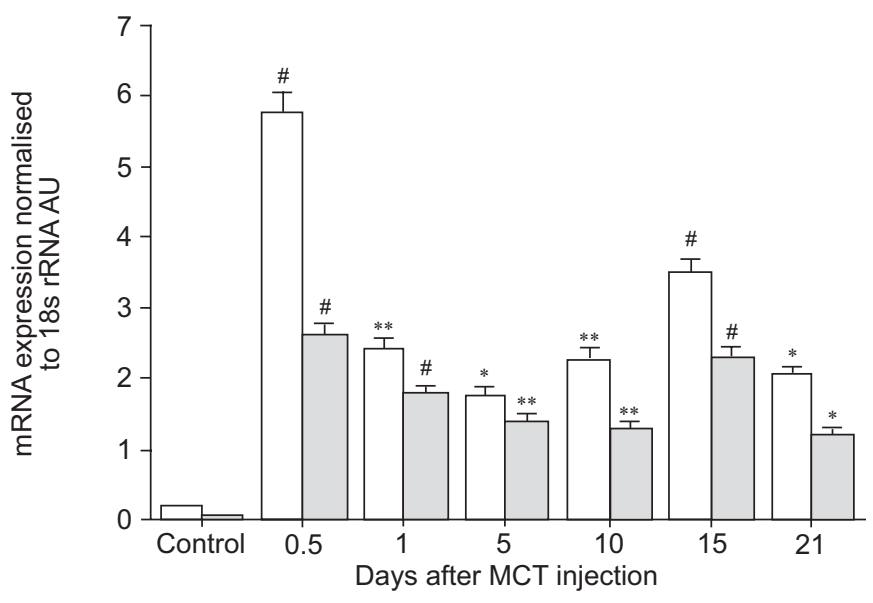

FIGURE 1. Fractalkine (CX3CL1) and fractalkine receptor (CX3CR1) expression in rat lungs. CX3CL1 $(\square)$ and $\mathrm{CX} 3 \mathrm{CR} 1(\square)$ expression was measured by means of real-time PCR before and after monocrotaline (MCT) exposure. There was a marked overexpression of CX3CL1 and CX3CR1 after MCT exposure. The whiskers represent SEM. AV: arbitrary units. *: $p<0.05$ versus control; **: $p<0.01$ versus control; ${ }^{\#}: p<0.0001$ versus control.
CD3, CD68, CX3CL1 and CX3CR1 staining by immunohistochemistry in pulmonary arteries from monocrotaline-exposed rats

Immunohistochemistry demonstrated that perivascular inflammatory cells from pulmonary hypertensive rats corresponded to CD68-positive macrophages and CD3-positive lymphocytes. In addition, CX3CL1 stained PASMC weakly and perivascular inflammatory cells strongly, while CX3CR1positive cells consisted of both PASMC and perivascular inflammatory cells. Stained Western blot analysis of culture PASMC indicated a production of CX3CR1 with expected bands at 27 and $30 \mathrm{kDa}$ (fig. 3) [29].

\section{CX3CL1-induced proliferation of rat pulmonary artery smooth muscle cells}

$\left[{ }^{3} \mathrm{H}\right]$ thymidine incorporation in PASMC in response to CX3CL1 and PDGF-BB indicated that both CX3CL1 and PDGF-BB could promote PASMC proliferation (fig. 4). There was no difference in terms of CX3CL1-induced proliferation between PASMC obtained from control and pulmonary hypertensive rats (data not shown).

\section{Lack of CX3CL1-induced migration of rat PASMC}

The process of chemotaxis can be measured at its initiation by evaluating actin polymerisation within cells, a physiological requirement for cell movement. No actin polymerisation could be demonstrated with CX3CL1 stimulation in PASMC, whereas a significant polymerisation occurred in response to PDGF-BB stimulation (fig. 5). These results were confirmed by a transwell assay showing that CX3CL1 could not promote PASMC migration, whereas a dose-response cell migration was demonstrated with PDGF-BB ( $p<0.0001$; fig. 6).

\section{DISCUSSION}

Experimental pulmonary hypertension in rats is associated with CX3CL1 and CX3CR1 overexpression, indicating a possible role for this chemokine in the pathogenesis of pulmonary hypertension, as previously suggested by data obtained in human PAH subjects by the current authors. In addition, the current authors demonstrated that rat PASMC express CX3CR1 and that PASMC proliferated but did not migrate in response to CX3CL1. Therefore, it is hypothesised that CX3CL1 overexpression may not only promote cell recruitment, but that it may also play a direct role in pulmonary artery remodelling, owing to its PASMC proliferative effect.

A feature common to all forms of pulmonary hypertension remodelling is the appearance of a layer of smooth muscle cells in small, peripheral, normally nonmuscular pulmonary arteries within the respiratory acinus [2]. The cellular processes underlying muscularisation of this distal part of the pulmonary arterial tree are not completely understood. This cellular proliferation results in chronic obstruction of small pulmonary arteries, an important characteristic of $\mathrm{PAH}$, and one which explains the presence of raised pulmonary vascular resistance. In human $\mathrm{PAH}$, several mediators may promote PASMC proliferation, including serotonin, endothelin-1, transforming growth factor- $\beta$ and PDGF [3]. In addition, germline mutations of the bone morphogenetic protein receptor type II gene detected in a significant proportion of familial and idiopathic $\mathrm{PAH}$ has clearly underlined that abnormal cellular growth is 

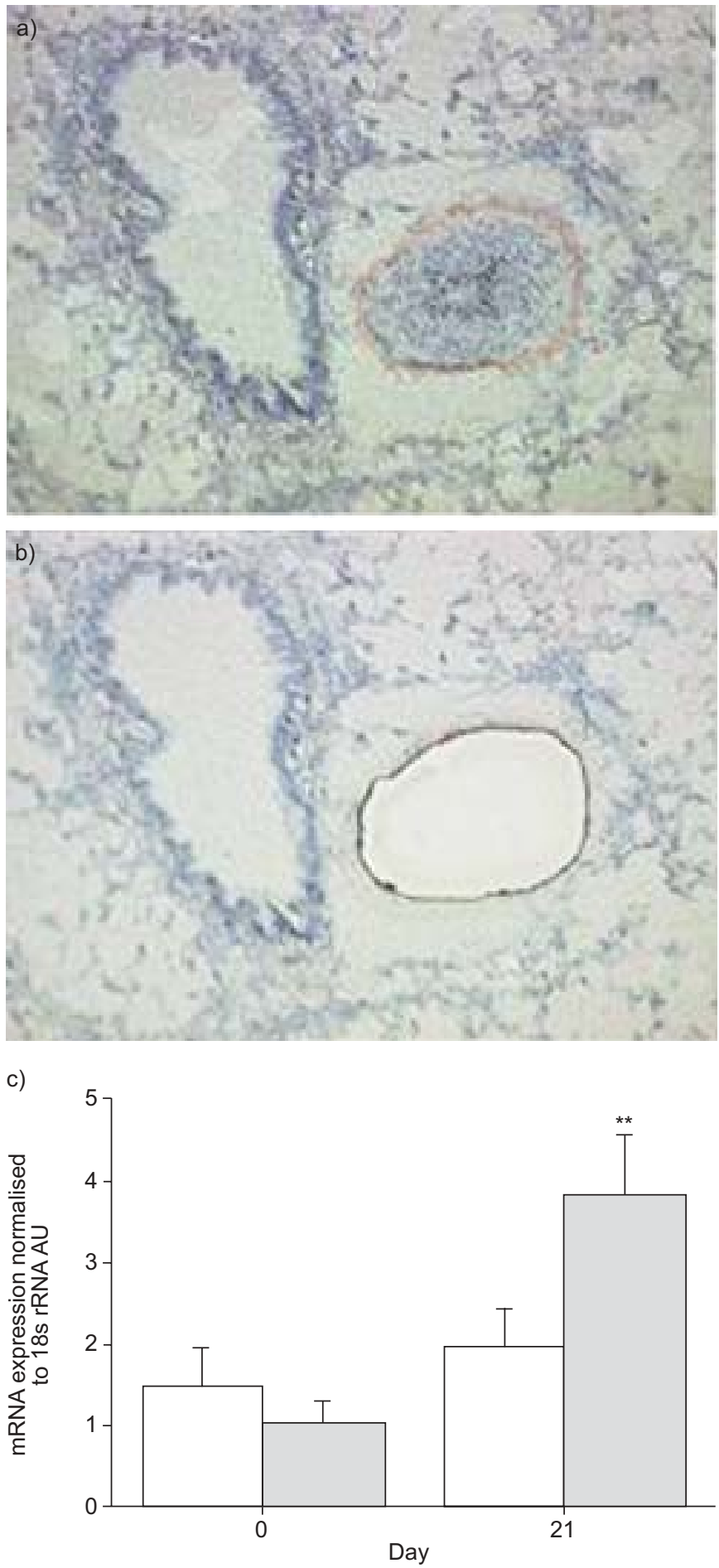

FIGURE 2. A microdissection of small and medium bronchus-associated pulmonary arteries is shown in a and b), respectively. c) Analysis of microdissected arteries showed that fractalkine $(\square)$ was not overexpressed, while there was a marked overexpression of fractalkine receptor $(\square)$. The whiskers represent SEM. AV:arbitrary units. **: $p<0.01$ versus control.

certainly a key feature of all types of pulmonary hypertension $[8,9]$. The present data add CX3CL1 to the list of agents able to promote PASMC proliferation and, by inference, remodelling and obstruction of small pulmonary arteries, although one of the limitations of the present study lies in the fact that no specific CX3CL1 antagonist was used to counterbalance its effects. The effect of CX3CL1 on CX3CR1-bearing PASMC is in keeping with recent data obtained in smooth muscle cells from atherosclerotic plaques [32].

The initial hypothesis was that chemokines, such as CX3CL1 and RANTES (regulated upon activation, normal T-cell expressed and secreted; CCL5), may induce pulmonary vascular inflammatory cell recruitment and therefore promote inflammatory damage leading to abnormal scarring and remodelling of pulmonary arteries. Although this predominant inflammatory component is presumably of significant importance in active inflammatory conditions such as systemic lupus erythematosus, a condition which may be reversible when treated with anti-inflammatory agents, it is debatable whether it plays a key role in other forms of symptomatic PAH, such as idiopathic and familial PAH. However, the current authors and other studies $[5,15,16]$ have demonstrated that inflammatory cells may indeed infiltrate small remodelled pulmonary arteries in the setting of established idiopathic PAH. Nevertheless, anti-inflammatory agents are usually ineffective in idiopathic PAH and the exact role of inflammatory cells and their mediators remains uncertain in this setting. The current authors hypothesise that these cells and mediators may either play a role early in the course of the disease prior to the development of end-stage fixed pulmonary vascular obstruction, or that they may contribute to disease progression. In order to support the latter hypothesis the current authors proposed that inflammatory mediators in general (and more precisely chemokines such as CX3CL1) may act beyond inflammatory cell recruitment. This is in keeping with the present data produced in experimental pulmonary hypertension showing a proliferative effect of CX3CL1 on PASMC.

Endothelial cell dysfunction is another hallmark of PAH, and reduced production of endothelium-derived prostacyclin and nitric oxide, as well as increased production of endothelin-1, are characteristic of the disease [3]. This endothelial dysfunction will in turn promote PASMC constriction and growth. Novel therapeutic strategies targeting these dysfunctional pathways have been shown to improve clinical and haemodynamic parameters in patients displaying severe PAH [1]. The current authors have previously found that pulmonary endothelial cells are the major pulmonary artery source of CX3CL1 in human PAH [15] and thus proposed that dysfunctional PAH pulmonary endothelial cells may be also characterised by elevated production of CX3CL1; this in turn may promote not only inflammatory cell recruitment but also PASMC growth. Monocrotaline-induced pulmonary hypertension is a useful model of pulmonary hypertension. Although this model highlights some components of pulmonary hypertension pathogenesis, such as exaggerated pulmonary vascular inflammation, the monocrotaline animal model of pulmonary hypertension presents striking differences with human PAH. The development of PAH in humans usually takes years and the role of inflammatory processes is not clinically predominant in idiopathic PAH. In contrast, monocrotaline exposure in rats induces acute "toxic" pulmonary artery endothelial cell damage, rapidly followed by a significant inflammatory reaction and subsequent obstruction of small pulmonary arteries by proliferating PASMC. These events lead to 

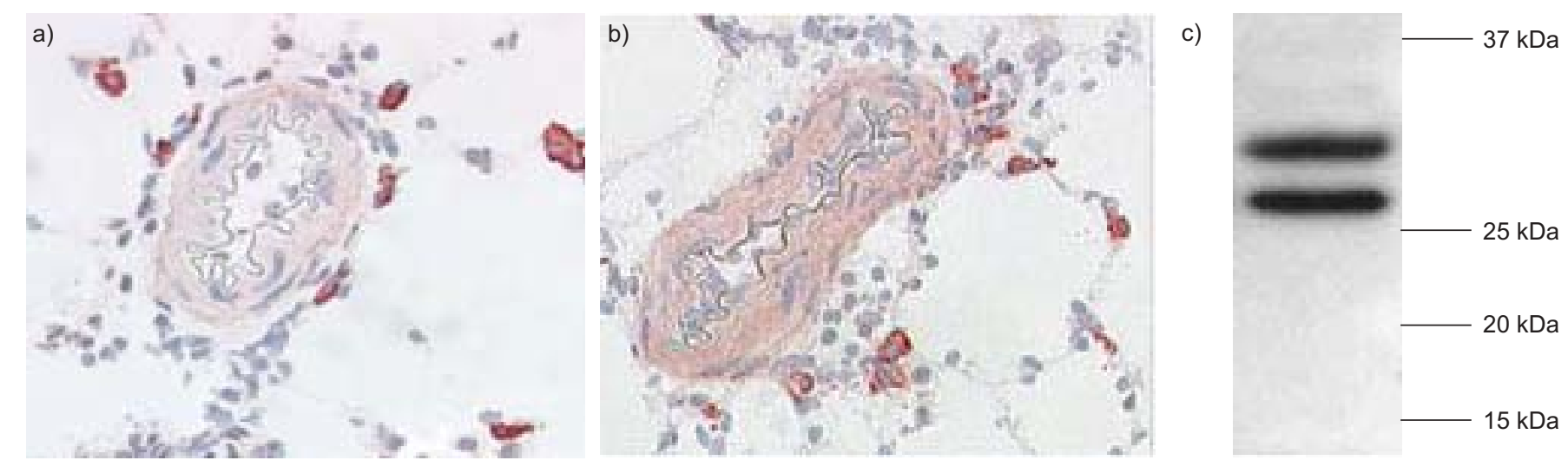

FIGURE 3. Immunhistochemical and western-blotting analysis of fractalkine (CX3CL1) and fractalkine receptor (CX3CR1) in pulmonary arteries from monocrotalineexposed rats. a) Immunohistochemical analysis of lungs from pulmonary hypertensive rats showed that CX3CL1 stained pulmonary artery endothelial and smooth muscle cells (PASMC) weakly and perivascular inflammatory cells strongly, while b) CX3CR1-positive cells included both PASMC and perivascular inflammatory cells. c) Western blot analysis of PASMC confirmed production of CX3CR1 with expected bands at 27 and $30 \mathrm{kDa}$.

significant pulmonary hypertension 14-21 days after exposure [33]. Interestingly, the present data show that CX3CL1 and its receptor were markedly overexpressed during the early inflammatory burst, with a peak detected as early as $12 \mathrm{~h}$ after monocrotaline exposure. However, CX3CL1/CX3CR1 gene expression remained elevated during the whole course of the disease after exposure when PASMC proliferation is a key event. In spite of the obvious weaknesses of the monocrotaline model, it has been successfully used to validate important concepts, which were later confirmed in human PAH (for instance major pharmaceutical agents widely used in $\mathrm{PAH}$, such as prostacyclin derivatives, phosphodiesterase type-5 inhibitors and endothelin receptor antagonists, have

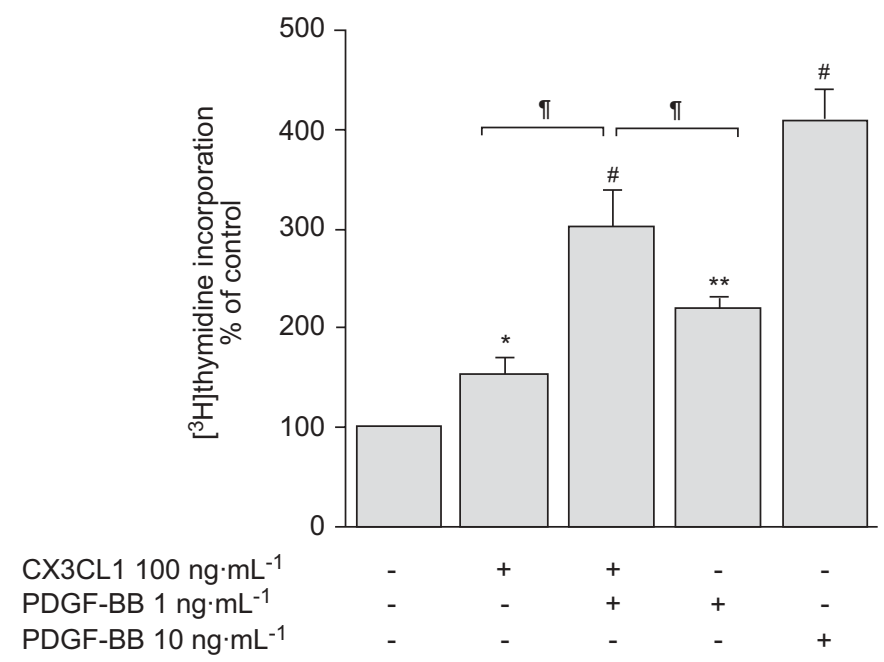

FIGURE 4. Fractalkine (CX3CL1)-induced proliferation of rat pulmonary artery smooth muscle cells (PASMC). PASMC proliferation in response to CX3CL1 and platelet-derived growth factor (PDGF)-BB stimulation was measured by means of $\left[{ }^{3} \mathrm{H}\right]$ thymidine incorporation. It was found that both CX3CL1 and PDGF-BB could promote PASMC proliferation. The whiskers represent SEM. *: $p<0.05$ versus control; ${ }^{* *}: p<0.01$ versus control; ${ }^{*}: p<0.0001$ versus control; ${ }^{\natural}: p<0.05$ versus other conditions. been tested in this model and later in large placebo-controlled trials in human PAH). Furthermore, several inflammatory conditions, such as connective tissue diseases, Hashimoto's thyroiditis and HIV infection, can lead to PAH. Autoimmunity is also a common denominator in several forms of PAH.

Chemokine antagonists such as anti-monocyte chemotactic protein-1 antibodies have been shown to successfully prevent monocrotaline-induced pulmonary hypertension in rats [34], and the current authors propose that chemokine antagonists may act, at least in part, as anti-remodelling agents. However, whether this potential therapeutic approach to reduce PASMC chemokine-induced growth will be successful in human PAH remains to be demonstrated. Recent data indicate that imatinib is able to inhibit PDGF-induced PASMC proliferation and can prevent monocrotaline-induced pulmonary hypertension in

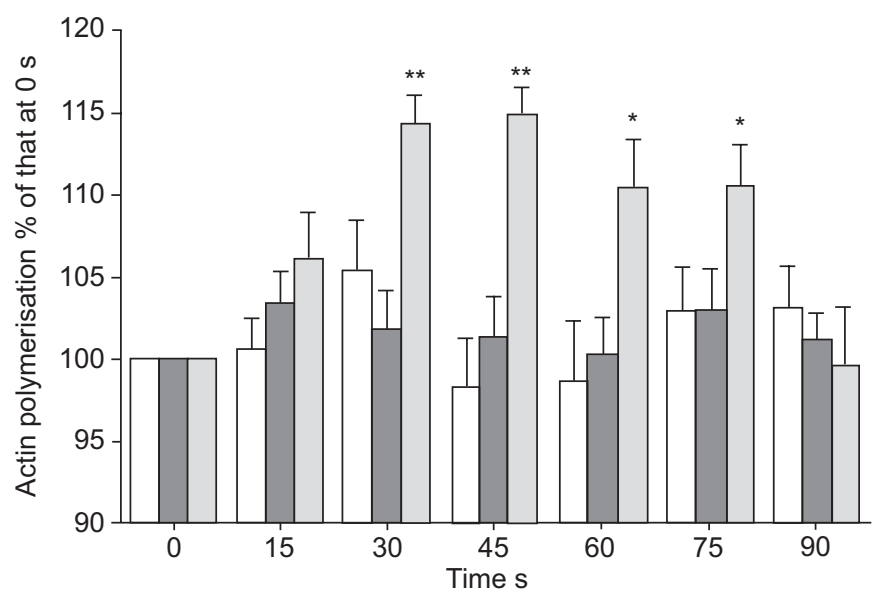

FIGURE 5. Lack of fractalkine-induced actin polymerisation in rat pulmonary artery smooth muscle cells. No actin polymerisation could be demonstrated with fractalkine stimulation $(\bullet)$ in pulmonary artery endothelial and smooth muscle cells, whereas a significant polymerisation occurred in response to platelet-derived growth factor-BB stimulation ( $\square$ ). $\square$ : controls. The whiskers represent SEM. *: $p<0.05$ versus control; **: $p<0.01$ versus control. 


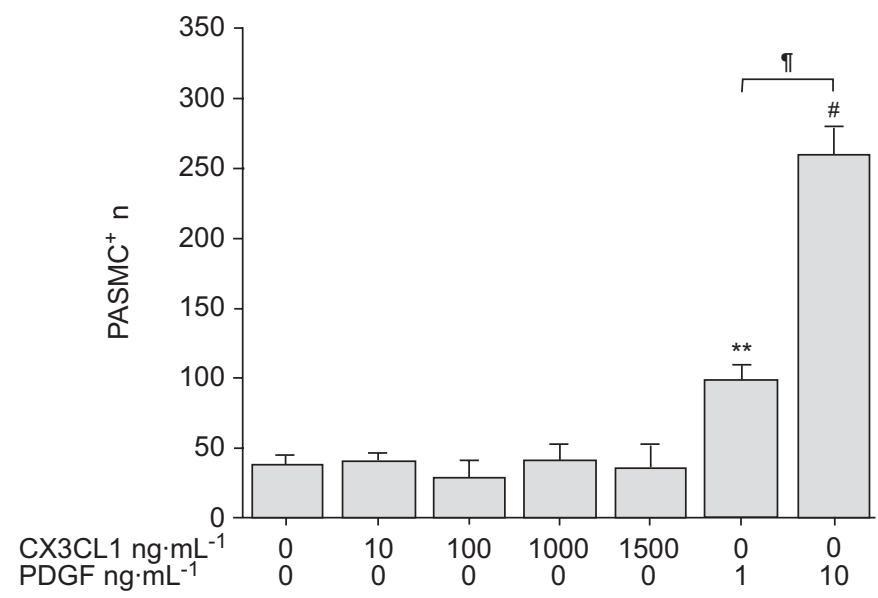

FIGURE 6. Lack of fractalkine (CX3CL1)-induced migration of rat pulmonary artery smooth muscle cells (PASMC). Transwell assay demonstrated that CX3CL1 could not promote PASMC migration whereas a dose-response cell migration was demonstrated with platelet-derived growth factor (PDGF)-BB. The whiskers represent SEM. **: $p<0.01$ versus control; \#: $p<0.0001$ versus control; ? $\mathrm{p}<0.0001$ versus PDGF-BB $1 \mathrm{ng} \cdot \mathrm{mL}^{-1}$; ${ }^{+}$: determined by light microscopy highpower $(\times 200)$ field.

rats [11]. Of note, preliminary case reports plead in favour of imatinib as an anti-remodelling agent in severe human $\mathrm{PAH}$ $[12,13]$. These preliminary data need to be confirmed in welldesigned placebo-controlled studies. Similarly, treatment strategies based on chemokine antagonism also require proper testing.

CX3CR1 has two common coding polymorphisms, namely V249I and T280M, that are in strong linkage disequilibrium and have been associated with interindividual differences in susceptibility to both HIV infection and atherosclerosis [35]. A significant association has been reported between coronary vascular endothelial dysfunction in humans and a polymorphism in the CX3CR1 gene that affects receptor expression and ligand-binding affinity [36]. Most important is the strong association found between this polymorphism and both the extent and complications of coronary artery disease, independent of established risk factors, suggesting a link between reduced CX3CR1 expression/function and the prevalence and severity of atherosclerosis.

Increased expression of CX3CL1/CX3CR1 may be a mere consequence of the abnormal haemodynamic status in the experimental pulmonary hypertension setting; however, the monocrotaline rat model clearly indicates that CX3CL1 overexpression occurred several days before the development of abnormal pulmonary haemodynamics, and that locally produced CX3CL1 may indeed act as a growth factor for PASMC expressing CX3CR1. The present data strongly support the concept that inflammatory cell-derived CX3CL1 may interact with CX3CR1 at the cell surface of PASMC and subsequently promote cell proliferation.

Therefore, the current authors conclude that the present data add fractalkine to the list of proliferative agents which may actively contribute to pulmonary artery endothelial and smooth muscle cell proliferation in pulmonary hypertension.
Further studies are needed to confirm and extend these findings, with the aim of identifying novel therapeutic pathways in pulmonary arterial hypertension.

\section{REFERENCES}

1 Humbert M, Sitbon O, Simonneau G. Treatment of pulmonary arterial hypertension. N Engl J Med 2004; 351: 1425-1436.

2 Pietra GG, Capron F, Stewart S, et al. Pathologic assessment of vasculopathies in pulmonary hypertension. J Am Coll Cardiol 2004; 43: 25S-32S.

3 Humbert M, Morrell NW, Archer SL, et al. Cellular and molecular pathobiology of pulmonary arterial hypertension. J Am Coll Cardiol 2004; 43: 13S-24S.

4 Barst RJ, McGoon M, Torbicki A, et al. Diagnosis and differential assessment of pulmonary arterial hypertension. J Am Coll Cardiol 2004; 43: 40S-47S.

5 Tuder RM, Voelkel NF. Pulmonary hypertension and inflammation. J Lab Clin Med 1998; 132: 16-24.

6 Montani D, Achouh L, Marcelin AG, et al. Reversibility of pulmonary arterial hypertension in $\mathrm{HIV} / \mathrm{HHV} 8$-associated Castleman's disease. Eur Respir J 2005; 26: 969-972.

7 Sanchez O, Sitbon O, Jais X, et al. Immunosuppressive therapy in connective tissue diseases associated pulmonary arterial hypertension. Chest 2006; 130: 182-189.

8 Humbert M, Trembath RC. Genetics of pulmonary hypertension: from bench to bedside. Eur Respir J 2002 20: 741-749.

9 Trembath RC, Thomson JR, Machado RD, et al. Clinical and molecular genetic features of pulmonary hypertension in patients with hereditary hemorrhagic telangiectasia. $N$ Engl J Med 2001; 345: 325-334.

10 Humbert M, Monti G, Fartoukh M, et al. Platelet-derived growth factor expression in primary pulmonary hypertension: comparison of HIV seropositive and HIV seronegative patients. Eur Respir J 1998; 11: 554-559.

11 Schermuly RT, Dony E, Ghofrani HA, et al. Reversal of experimental pulmonary hypertension by PDGF inhibition. J Clin Invest 2005; 115: 2811-2821.

12 Souza R, Sitbon O, Parent F, Simmoneau G, Humbert M. Long-term imatinib therapy in pulmonary arterial hypertension. Thorax 2006; 61: 736.

13 Ghofrani HA, Seeger W, Grimminger F. Imatinib for the treatment of pulmonary arterial hypertension. $N$ Engl J Med 2005; 353: 1412-1413.

14 Humbert M, Monti G, Brenot F, et al. Increased interleukin1 and interleukin-6 serum concentrations in severe primary pulmonary hypertension. Am J Respir Crit Care Med 1995; 151: 1628-1631.

15 Balabanian K, Foussat A, Dorfmuller $\mathrm{P}$, et al. $\mathrm{CX}_{3} \mathrm{C}$ chemokine fractalkine in pulmonary arterial hypertension. Am J Respir Crit Care Med 2002; 165: 1419-1425.

16 Dorfmuller P, Zarka V, Durand-Gasselin I, et al. Chemokine RANTES in severe pulmonary arterial hypertension. Am J Respir Crit Care Med 2002; 165: 534-539.

17 Bazan JF, Bacon KB, Hardiman G, et al. A new class of membrane-bound chemokine with a $\mathrm{CX} 3 \mathrm{C}$ motif. Nature 1997; 385: 640-644.

18 Harrison JK, Jiang Y, Chen S, et al. Role for neuronally derived fractalkine in mediating interactions between 
neurons and CX3CR1-expressing microglia. Proc Natl Acad Sci U S A 1998; 95: 10896-10901.

19 Harrison JK, Jiang Y, Wees EA, et al. Inflammatory agents regulate in vivo expression of fractalkine in endothelial cells of the rat heart. J Leukoc Biol 1999; 66: 937-944.

20 Imaizumi T, Yoshida H, Satoh K. Regulation of CX3CL1/ fractalkine expression in endothelial cells. J Atheroscler Thromb 2004; 11: 15-21.

21 Lucas $\mathrm{AD}$, Chadwick N, Warren BF, et al. The transmembrane form of the CX3CL1 chemokine fractalkine is expressed predominantly by epithelial cells in vivo. Am J Pathol 2001; 158: 855-866.

22 Imai T, Hieshima K, Haskell C, et al. Identification and molecular characterization of fractalkine receptor CX3CR1, which mediates both leukocyte migration and adhesion. Cell 1997; 91: 521-530.

23 Umehara H, Bloom ET, Okazaki T, Nagano Y, Yoshie O, Imai T. Fractalkine in vascular biology: from basic research to clinical disease. Arterioscler Thromb Vasc Biol 2004; 24: 34-40.

24 Wong BW, Wong D, McManus BM. Characterization of fractalkine (CX3CL1) and CX3CR1 in human coronary arteries with native atherosclerosis, diabetes mellitus, and transplant vascular disease. Cardiovasc Pathol 2002; 11: 332-338.

25 Lesnik P, Haskell CA, Charo IF. Decreased atherosclerosis in CX3CR1-/- mice reveals a role for fractalkine in atherogenesis. J Clin Invest 2003; 111: 333-340.

26 Chandrasekar B, Mummidi S, Perla RP, et al. Fractalkine (CX3CL1) stimulated by nuclear factor $\kappa \mathrm{B}(\mathrm{NF}-\kappa \mathrm{B})$-dependent inflammatory signals induces aortic smooth muscle cell proliferation through an autocrine pathway. Biochem J 2003; 373: 547-558.

27 Stinger RB, Iacopino VJ, Alter I, Fitzpatrick TM, Rose JC, Kot PA. Catheterization of the pulmonary artery in the closed-chest rat. J Appl Physiol 1981; 51: 1047-1050.
28 Eddahibi S, Fabre V, Boni C, et al. Induction of serotonin transporter by hypoxia in pulmonary vascular smooth muscle cells. Relationship with the mitogenic action of serotonin. Circ Res 1999; 84: 329-336.

29 Garin A, Tarantino N, Faure S, et al. Two novel fully functional isoforms of CX3CR1 are potent HIV coreceptors. J Immunol 2003; 171: 5305-5312.

30 Eddahibi S, Humbert M, Fadel E, et al. Serotonin transporter overexpression is responsible for pulmonary artery smooth muscle hyperplasia in primary pulmonary hypertension. J Clin Invest 2001; 108: 1141-1150.

31 Foussat A, Bouchet-Delbos L, Berrebi D, et al. Deregulation of the expression of the fractalkine/fractalkine receptor complex in HIV-1-infected patients. Blood 2001; 98: 1678-1686.

32 Lucas AD, Bursill C, Guzik TJ, Sadowski J, Channon KM, Greaves DR. Smooth muscle cells in human atherosclerotic plaques express the fractalkine receptor CX3CR1 and undergo chemotaxis to the $\mathrm{CX} 3 \mathrm{C}$ chemokine fractalkine (CX3CL1). Circulation 2003; 108: 2498-2504.

33 Meyrick B, Gamble W, Reid L. Development of Crotalaria pulmonary hypertension: hemodynamic and structural study. Am J Physiol 1980; 239: H692-H702.

34 Kimura H, Kasahara Y, Kurosu K, et al. Alleviation of monocrotaline-induced pulmonary hypertension by antibodies to monocyte chemotactic and activating factor/ monocyte chemoattractant protein-1. Lab Invest 1998; 78: 571-581.

35 Moatti D, Faure S, Fumeron F, et al. Polymorphism in the fractalkine receptor CX3CR1 as a genetic risk factor for coronary artery disease. Blood 2001; 97: 1925-1928.

36 McDermott DH, Halcox JP, Schenke WH, et al. Association between polymorphism in the chemokine receptor CX3CR1 and coronary vascular endothelial dysfunction and atherosclerosis. Circ Res 2001; 89: 401-407. 